\title{
LORETTA AND GREG'S STORY
}

Walking up to Loretta's front door on the outskirts of a midsized town in Mississippi presents something of a challenge. Her neighborhood was built on a swamp, and the developer has not planted lawns or put in proper drainage. After a few rainy days, the ground between the street and her door is inches deep in slushy Mississippi mud.

The chaotic signs of poverty that mark her neighborhood-rusting cars in driveways, a broken washing machine in front of a house, muddy and cluttered lawns-are a far cry from the orderly military-base housing in which Loretta, the blue-eyed daughter of a career army man, grew up. With a love of literature and hopes of becoming a veterinarian, Loretta believed in the American dream. Her father was securely employed in a setting that guaranteed good health care and other benefits for his family. Loretta, with her long hair, bright eyes, and glowing complexion, fit in well in the stable working-class communities where she spent her youth. In 1990, she married Greg, a selfemployed flooring subcontractor dedicated to precision in his craft, and envisioned a comfortable life with a chance to move up the ladder of opportunity.

But times changed, and life, as Loretta reiterates, doesn't always turn out the way you planned. 
In early 2003, she heard through a friend at her job at Mississippi State University that some visiting professors were interested in hearing how families without health insurance try to scrape by. Loretta signed up right away.

And that is how we found ourselves gingerly navigating our way from the curb to Loretta's front door, as she called out instructions about how to step down in the few spots where it was possible to walk without mucking up our shoes too badly.

\section{PHYSICAL CUES}

Loretta welcomes us warmly, offering us seats on a torn couch and an unsteady chair in the room that serves as entrance hall, living room, dining room, and play room. She apologizes for the blotches of mud that her five children (ages one to eleven), several cats, three dogs, and various other assorted pets have tracked into the house.

It is hard to piece together the physical cues that would allow us to guess Loretta's age. Her white skin is smooth and unwrinkled, and her long hair has no gray; but her sagging breasts and belly seem to belong to a much older woman. Her eyes are clear and animated, but she squints to see us-she needs glasses, "but they charge an arm and a leg for them." She had a pair of glasses when she was on Medicaid during her last pregnancy, but the kids broke them. She tells us that she manages okay without them, except when she drives. She is wearing an oversized t-shirt, somewhat faded and stained, and no shoes ("too much mud, it's not worth it"). Her hair is mussed up by the baby and a toddler, who take turns sitting on her lap.

But the most striking aspect of her appearance is her teeth, or, to be more accurate, the absence of most of her teeth. She tells us, "I've gotten toothaches so bad, so that I just literally pull my own teeth. They'll break off after a while, and then you just grab ahold of them, and they work their way out."

We ask how she can face the pain of pulling out her own teeth. 
"It actually feels-it hurts so bad, because the tooth aches. Then it's a relief just to get it out of there. The hole closes up itself anyway. So it's so much better."

Loretta tells us that if President Bush were to change his mind and make health care available to all Americans, the first thing she would do is go to the dentist. "I've gone two weeks with being able to eat just soup, because my teeth just hurt so bad."

\section{HUSBANDS, BABIES, AND TEMPORARY EMPLOYMENT}

Loretta has not had adequate health care since she married her husband thirteen years ago. Because Greg is a construction specialist, he and the family move frequently, going "wherever they are doing a lot of building." His work tends to be seasonal, and the winter months are difficult for the family. In good months, he might earn as much as $\$ 2,500$; in other months, he brings in as little as $\$ \mathrm{I}, 000$; and in some months, nothing at all. Like many self-employed Americans, Greg cannot afford to carry health insurance for himself, much less for his family.

Loretta has begun to work nights at a university research center, making calls for a telephone survey lab. She loves the work and enjoys getting out of the house and talking to people. Unfortunately, the work is temporary, only part-time, and does not offer health insurance.

"My husband is one of those [who has], I think, a real macho attitude, where the woman is supposed to stay at home and take care of the children and clean the house and cook the food. And he's going to go out and work. This last year, he's finally started to realize that it does help a little bit if I go out and work."

Loretta, a devoted mother, feels stretched to her limit with five children, but Greg is a member of the Church of Jesus Christ of Latter Day Saints (Mormons) and won't hear of a tubal ligation. "I tried very hard after this last one to convince him to let me have my tubes tied, but he was adamant that this is just not happening. His way of thinking-for religious reasons, he doesn't want it done. Because it's just not natural 
for a woman to have her tubes tied. And, you know, if God wants you to have babies, then you're going to have one. If He doesn't want you to have it, you're not going to have it. Okay! Well, but it's me that has to carry it for the nine months, you know, with the morning sickness all day long through the whole nine months!"

Though their family income would seem to be low enough to qualify her for Medicaid during her pregnancies, she has had trouble with the enrollment process. She applied during her first pregnancy but was turned down because she did not have a proper U.S. birth certificate. (She was born in Germany when her father was serving there in the U.S. Army.) She wrote to the U.S. State Department, paid \$40, and received a birth certificate signed by Madeleine Albright in time for her second pregnancy. But in the many moves the family has made to follow construction booms around the country, Loretta misplaced the birth certificate and thus had no Medicaid coverage or prenatal care for her third pregnancy. By the time of her last pregnancy, she had written again to Washington, this time receiving a certificate signed by Colin Powell. Loretta playfully describes herself as a friend of not one but "two secretaries of state!"

Loretta was given birth control pills after her first two "back-to-back" babies. Six months later, she had a heart attack, which the doctor seems to have attributed to the pills. She has not had an EKG or any follow-up care since. She is hesitant about using birth control pills again, especially in the absence of ongoing supervision by a physician whom she can get to know and trust. Dependent on free family-planning services, she rarely sees the same provider twice.

\section{SCRAPING BY ON MOLOTOV COCKTAILS}

Six weeks after the birth of her fifth child, Loretta was again taken off the Medicaid rolls. "I refuse to get sick. And, like all mothers, you just can't afford to be sick anyway. And if I get sick, I mainly go and do. When I can afford over-the-counter medication, I'll buy everything I 
can get my hands on. Just a 'Molotov cocktail' of everything, you know. NyQuil is really good. The Vick's cough syrup. We keep stock in BC powders [a popular over-the-counter headache remedy in the South] and Advil, the liquid gels. Cough drops, cough syrup." Loretta estimates that she spends about I $_{5}$ O a month on over-the-counter medicines.

Fortunately, her children are covered by Medicaid, which in most states has more liberal income limits for children than for their parents. "As a matter of fact, if it weren't for Medicaid for the kids, I couldn't even tell what I would do. Because they've been, oh, they stay constantly sick. You know, with a cold. Last year, I caught pneumonia with the three-year-old, and I've been fighting bronchitis with my one-year-old. My oldest one has allergies that are so severe that if he doesn't take his medication, he'll walk around with a bloody nose constantly. This is only since we moved here to Mississippi."

The reasons they are sick so often, Loretta explains, have to do with the living conditions and the absence of good public services. The nearest supermarket is a Wal-Mart four miles away. To reach the food department, Loretta has to walk with her kids through the clothing and toy departments, a route that makes each trip an adventure in patience. More often, she uses the convenience store located two and a half miles away, which unfortunately does not carry much in the way of fresh food.

Loretta tells us that she and her neighbors are worried about the swamp right in the middle of the neighborhood. "It's breeding territory for mosquitoes, and last year I know [the city government] didn't come out and spray."

Women in the neighborhood further attribute their children's poor health to the mediocre quality of the available medical care. Loretta introduces us to her closest friend, Robin, whose children were turned down for Medicaid. Robin recalls, "I took my son and our neighbor's son in to the hospital because they'd gotten into a whole bunch of pesticide. He was eating it off his fingers, and it was on the mouth of the neighbor's child. The first thing it says on the bag is to induce vomiting. But the doctor looked at me and said, 'Okay, he's fine. Sign those papers, and 
you can go home.' The doctor didn't [examine the kids or] come to me and explain nothing. He didn't even follow the prescribed guidelines. I mean, that was just totally outrageous in my eyes."

Loretta confirms that the care at the local emergency room often is less than optimal, at least for uninsured patients. "I had to go to the emergency room just last week. I had a sinus infection, and it was so bad that the side of my face was swollen. And the doctor just came in and looked at me and said, 'Oh, you've got a sinus infection.' I mean, did he bother? He didn't do any [tests or exam] . . . . I thought to myself, 'I hope that's what it is. And I'm glad you're giving me the antibiotics.' But what if something else were the problem?"

Loretta has not yet received the bill for her last emergency room visit, but the antibiotics alone cost her $\$ 100$. She knows that she will not be able to pay the bill when it arrives, and she knows that it will go to a collection agency. The debt will go on her credit record and cause problems later if she wants to get a credit card, lease a vehicle, or rent an apartment.

While Loretta considers herself reasonably healthy, she does suffer from frequent migraines accompanied by violent vomiting. We ask whether she has seen a doctor about the migraines.

"The one time I went to see a doctor with them, the doctor looked at me- and this was really years before they realized that migraines are an actual thing-the doctor looked at me and told me it was my imagination. And I asked him, I said, 'Well, don't you think if my imagination was that good that I would have imagined something a little bit better than a migraine headache?' And he did not appreciate me being flip. $\mathrm{He}$ just kind of looked at me and said, 'Well, there's nothing wrong with you. You need to leave.' And I'm like, 'Okay.”

Greg has some health problems of his own. He was injured when another car smashed into his, and he suffers from chronic elbow inflammation. At the time of his elbow surgery, his blood pressure was high. "And it's probably something that he needs to have medication for, but even if we could afford to go to the doctor for it, I know we couldn't afford 
the medication." He suffers from constant headaches, which Loretta suspects are linked to the high blood pressure.

Greg also has ulcers, diagnosed when he was a teenager, but he has not been examined by a doctor for nearly thirteen years. "He keeps stock in Rolaids and Tums and Pepcid AC and Zantac," Loretta jokes. Over the past few months, his stomach troubles have become worse: "He throws up whatever he eats. He just-he gets cranky." The large hole he punched in the living room wall when a customer didn't pay him for his work attests to his crankiness.

Over the course of several conversations, Loretta spoke at length about the stress of choosing between buying food and buying medicine, the stress of working in temporary and seasonal jobs, the stress of feeling trapped in circumstances of poverty that she cannot control, the stress of living with a man who is often angry and frustrated that he cannot provide for his family, and, above all, the stress of living with chronic illnesses and chronic pain that she does not have the resources to remedy.

Loretta is brilliant at scraping by. We ask her how the cost of medicine fits into her very tight household budget.

"You just find a way. Say, for instance, I need a bag of diapers and cough syrup. Instead of buying the big bag of diapers, you buy the smaller, and you're able to afford the one bottle of cough syrup." What she does when the small bag of diapers runs out, we don't have the courage to ask.

\section{THE CASTE OF THE WORKING POOR}

Loretta is illustrative of many of the people we met on our travels across America. Although she grew up in an economically stable working-class family, she now teeters on the brink of economic destitution. She is married to a man who opposes birth control for religious reasons and who works at seasonal jobs that do not provide health benefits. Despite her disagreements with her husband, Loretta is committed to the marriage and to raising the children with their father, and she has no immediate plans to leave him. 
Greg is self-employed in an occupation that, while necessary-we all enjoy having houses with floors-has frequent economic ups and downs. As a result, Loretta has not had consistent health care for fifteen years. During those years, her status has shifted: once a member of the working class, she is now a member of the caste of the ill, the infirm, and the marginally employed-a group often called by the more palatable name working poor.

Her physical appearance (missing and rotten teeth, a nearsighted squint, and her generally unkempt self-presentation) makes it unlikely that she can fulfill her dream of a job in a veterinarian's office, where she would be dealing with the public. She is more likely to be steered toward jobs like the one she found shortly before we met her-conducting a phone survey during the evening hours at the local university. In other words, Loretta is bright enough to participate in a university research project, but she is not considered presentable enough to work in an office where she would meet clients or research subjects face to face.

Loretta's work at the university is temporary, part-time, and deadend. Because she is a "temp," the university does not provide health insurance. Thus, she finds herself in a bind: as long as her only job opportunities result in dead-end positions (across the nation, telemarketing - where the employee is invisible-is one of the mainstays of the working poor, but such jobs rarely offer health insurance), she cannot access the health care she needs in order to make herself more presentable and pursue a better job with benefits.

Within the current social and health care framework, what are Loretta's options? The first is that she could leave her husband. Then, as a single mother with no income (without Greg to take care of the children in the evening, she would have to quit her job at the university), she would be eligible for welfare and Medicaid. But this choice would offer only temporary relief. Under the welfare reform legislation of the I $990 \mathrm{OS}$ her lifetime eligibility for public aid is limited to a set number of years, after which she would be back where she started, but without the income (however sporadic) provided by her husband. And, of course, this option 
involves breaking up a family-not exactly the intended goal of either the health care system or the current system of public aid.

The second option is to have another child in order to be eligible for Medicaid during the pregnancy. The downside here is that once a woman gives birth, her Medicaid coverage ends. Also, because Medicaid during pregnancy does not cover many nonpregnancy health problems, on balance another pregnancy (Loretta's sixth) would probably do more harm than good to her overall health. While this option certainly sounds foolish to us, we were told by a number of women we interviewed that this is precisely what the clerk or caseworker at the public aid office suggested when they applied for help with medical expenses.

Loretta's third option might be to pack up the family and try to move to a state that has more liberal cut-offs for Medicaid eligibility. But the family could face serious obstacles if they made a decision to move based on Medicaid benefits rather than on where Greg could most easily find work. If the family moved to an area without a good amount of available construction work, there is no guarantee that Greg would earn enough to pay the rent, which could leave them vulnerable to homelessness (a situation Loretta fears above all others). Small businesses like Greg's are notoriously difficult to start, and it would certainly take a while until he could generate enough business to support the family. They have no savings to get them through a slow start-up period, and Loretta, who is only marginally employable, probably could not earn enough to carry the burden.

We will never know which option she chose. A few months after we first met her, we went back to see how Loretta was doing. Her house was empty, the family had moved, and none of the neighbors knew where they had gone. At this time, we suspect, they are either camping out with relatives somewhere in the country, living in a homeless shelter, or about to be evicted from another house or apartment. 
